\title{
Pitfalls in estimating the $X$-factor: The case of energy transmission regulation in Brazil
}

\author{
Mohsen Afsharian \\ Technische Universität Braunschweig, Institute of Management Control and Business Accounting, \\ Fallersleber-Tor-Wall 23, D-38100 Braunschweig, Germany.Email: m.afsharian@tu-bs.de. \\ Heinz Ahn \\ Corresponding Author. Technische Universität Braunschweig, Institute of Management Control and \\ Business Accounting, Fallersleber-Tor-Wall 23, D-38100 Braunschweig, Germany. Phone: +49531 \\ 391-3610.Email:hw.ahn@tu-bs.de.
}

Ana Lopes

Universidade Federal de Minas Gerais, Av. Antonio Carlos, 6627, 31270-901, Pampulha-Belo Horizonte, Minas Gerais, Brazil.Email: analopes.ufmg@gmail.com.

Bruno Vilela

Universidade Federal de Minas Gerais, Av. Antonio Carlos, 6627, 31270-901, Pampulha - Belo Horizonte, Minas Gerais, Brazil.Email: brunoavilela@ufmg.br.

Date of first submission: 10 September 2017; date of re-submission: 16 February 2018

\begin{abstract}
In Brazil, which has one of the biggest energy systems in the world, the National Electricity Regulatory Agency (Agência Nacional de Energia Elétrica - ANEEL) regulates the generation, transmission, distribution and commercialization of electricity. As a key step in running the incentive regulation regime, the regulator applies a DEA-based Malmquist index for estimating the X-factor, which reflects productivity gains that can be expected across all companies involved in the industry. This paper investigates the way the X-factor was estimated in 2015 by ANEEL in the transmission sector concerning the review period 2009-2014. The regulator applies a modified version of the Malmquist index developed by Ray and Desli [1] and also adapts the bootstrapping method of Simar and Wilson [2] to generate confidence intervals for an estimate of the X-factor. Analyzing ANEEL's approach, we have discovered a number of serious analytical and computational shortcomings, which we demonstrate in the paper. On this basis, we address the effect of the estimated X-factor on social welfare, having the final customers to pay a higher price for electricity than they were supposed to.
\end{abstract}




\section{Keywords}

Data envelopment analysis; X-factor estimation; Energy transmission regulation

\section{Funding}

This work was supported by

- Deutsche Forschungsgemeinschaft (DFG) under Grant AH 90/5-1,

- Fundação de Amparo à Pesquisa do Estado de Minas Gerais (FAPEMIG) under Grant APQ-03165-11,

- Coordenação de Aperfeiçoamento de Pessoal de Nível Superior (CAPES) under Grant 999999.000003/2015-08,

- Conselho Nacional de Desenvolvimento Científico e Tecnológico (CNPq) under Grant 444375/2015-5.

None of these sponsors had any influence on our study.

\section{Conflict of interest}

There exists no conflict of interest. 


\section{Introduction}

Many network industries such as electricity, natural gas, water supply and telecommunication are natural monopolies mainly due to the high infrastructural investment required to produce and deliver products and/or services to customers. In the absence of perfect competition and the resulting market failure, operators in such network industries encounter fewer incentives towards efficiency improvement and cost saving opportunities. Most governments, therefore, set up regulation mechanisms to manage the behavior of the operators by ensuring that appropriate services at reasonable prices are delivered to customers, while not interfering into the day-to-day business of the operators and not discouraging innovation within the industry. Against this background, a variety of different regulatory approaches have emerged (see Section 2.1 for a brief overview of these approaches; a detailed review can also be found in, e.g., Bogetoft [3]).

In the context of electricity transmission in Brazil, the National Electricity Regulatory Agency (Agência Nacional de Energia Elétrica - ANEEL) regulates the sector by running a revenue cap system (Pessanha et al. [4]; ANEEL [5]). Within this approach, costs of operations are determined to fix the revenue for each transmission system operator (TSO) for a pre-determined regulatory period. As it will be shown later, the corresponding incentivization formula involves the expected efficient costs of operations of each TSO which are determined based upon the data in the last year of the review period. The formula also includes the X-factor, which reflects the productivity gain already obtained across all operators involved in the industry and therefore should be passed on to customers. This paper investigates details of the way the X-factor was estimated in 2015 by ANEEL in the transmission sector concerning the review period 20092014.

The X-factor is often set by applying a framework of the Malmquist index (MI) and analyzing the productivity change and its drivers over the years prior to the regulatory period. The earliest type of this index - which was proposed initially for consumption analysis - was introduced into the productivity literature by Caves et al. [6]. Their work was later adapted by Färe et al. [7] to the non-parametric approach. Färe et al. [7] suggested how data envelopment analysis (DEA) introduced by Charnes et al. [8] - could be used for measuring productivity changes over time. In the same paper, they also showed that the Malmquist index could be formulated as the product of

efficiency change (EC) and technical change (TC) components (known as FGLR - Färe, 
Grosskopf, Lindgren and $\underline{R}$ oos - decomposition of the Malmquist index). Since the publication of this work, there has been an extensive focus on the methodological development and application of the Malmquist index (for a detailed review, see, e.g., Afsharian and Ahn [9]).

Concerning the FGLR decomposition of the Malmquist index, Färe et al. [7] assumed that the benchmark technology exhibits constant returns to scale (CRS). Their approach was then developed further to provide a clearer picture of the root sources of productivity change by alternative decompositions of the Malmquist index. Especially, Färe et al. [10] included variable returns to scale (VRS) in the analysis and formulated the so-called FGNZ (프re, Grosskopf, Norris and Zhang) decomposition, which can capture the scale efficiency change (SEC). Ray and Desli [1], however, questioned the validity of the way both CRS and VRS are applied in the FGNZ decomposition in general and the use of CRS for the technical change component of the Malmquist index in particular. Accordingly, they developed the well-known RD (ㅁay and Desli) decomposition, which measures the technical change based on a VRS-based benchmark technology and provides a different interpretation of the scale efficiency change.

In order to estimate the X-factor, ANEEL applies a modified version of the above-mentioned RD decomposition of the Malmquist index. In its approach, the VRS assumption for the benchmark technology is replaced by non-decreasing returns to scale (NDRS). ANEEL also adapts the bootstrapping method of Simar and Wilson [2] to generate confidence intervals for initial estimates of the X-factor. However, its approach has a number of serious analytical and computational shortcomings.

The fundamental goal of this paper is to present an overview of ANEEL's approach to highlight these shortcomings and the resulting misleading managerial conclusions, which should be avoided in the future. More precisely, we analyze problems which have been found in the definition of the distance functions, the aggregation of the indices, the interpretation of the results as well as the application of the bootstrapping procedure. As a result of this careful analysis, we question the accuracy of the X-factor, estimated by ANEEL in the Brazilian TSO regulation. With both theoretical and empirical evidences, we argue that the $\mathrm{X}$-factor should have been set to a different value. As it will be discussed later in greater detail, the consequences are essential. On the one hand, the TSOs lack a proper incentive to improve their efficiency by lowering their 
costs, and on the other hand, there is a substantial impact on social welfare where consumers have to deal with higher energy tariffs.

The paper proceeds as follows: Section 2 reviews the fundamentals of incentive regulation, including a description of the revenue cap regime as well as the Malmquist index and its decompositions. On this basis, Section 3 gives a background on the energy transmission regulation in Brazil. Section 4 gives a critical overview of ANEEL's approach to estimating the $\mathrm{X}$-factor in 2015 concerning the time period 2009-2014. Section 5 summarizes our findings and provides further remarks.

\section{Fundamentals of regulatory regimes}

\subsection{A brief overview of the approaches}

Large infrastructure industries such as electricity, natural gas, water supply and telecommunication are natural monopolies mainly due to the high infrastructural investment and low marginal costs to produce and deliver products and/or services to customers. In the absence of perfect competition and the resulting market failure (due to having no close substitutes for the products/services), operators in such network industries encounter fewer incentives towards efficiency improvement and cost saving opportunities. In many countries, therefore, the governments empower regulators to manage the behavior of the operators by ensuring that appropriate services at reasonable prices are delivered to customers (Agrell and Bogetoft [11]).

The key issue in incentive regulation is that the regulators usually do not have sufficient information with respect to the true cost function of the agents (the monopolistic regulated companies) in delivering expected services to customers. The agents may take advantage of this asymmetry of information by lowering the effort really needed to be cost-efficient. Hence, regulators set up mechanisms to reduce the level of information asymmetry, avoiding as much as possible extra regulatory costs (Agrell and Bogetoft [11]). Furthermore, regulators often provide a balanced system to incentivize new investments (Arango [12]). They also have to define appropriate reimbursement schemes that benefit the society in a way that the value of the companies' stocks are not negatively affected (Nunez [13]). In the following, we give a brief overview of incentive approaches, which have widely been applied by regulators: 
- Cost recovery: In cost recovery regimes, the costs reported by the agents are fully reimbursed. Generally, accounting costs are taken into consideration and a markup parameter is established as a remuneration factor in this mechanism. It demands intense regulatory participation in order to guarantee the quality of the information provided and to avoid unnecessary operating expenses for the agents (see Laffont and Tirole [14]).

- Yardstick: In yardstick regimes, there is the attempt to simulate the market competition as closely as possible. These regimes define the target costs for each agent using actual costs of other comparable monopolistic agents. Accordingly, the maximum allowable revenue of an agent is determined on the basis of its relative performance compared to the other agents in the sector (see Shleifer [15]; Bogetoft and Tind [16]).

- Franchise auctions: Franchise bids are another form to mimic the competition, which limits the informational rents. Through the process of bidding, the regulator chooses the agent that can show to be the most efficient one in the auction. It is done by selecting the agent which offers the lowest (predicted) costs compared to the other agents in competition. In order for this process to be effective, the market should have a low level of concentration with a relatively high number of bidders (see Demsetz [17]).

- Fixed price: In fixed price regimes, the regulator sets a limit for the prices or revenue of the agents (price cap or revenue cap, respectively), prior to the regulatory period. This can be done by also incorporating an estimate of the X-factor, which reflects productivity gains that can be expected across all agents involved in the industry (Littlechild [18]; Bernstein and Sappington [19]). During the regulatory period, therefore, the agents may improve their efficiency and economize their costs in order to increase their profit (Liston [20]).

The main approach chosen for regulating the electricity sector in Brazil is the fixed price regime: price cap for electricity distribution (Lins et al. [21]) and revenue cap for electricity transmission (Pessanha et al. [4]). In the next section, we provide more details on the specific type of the revenue cap system which is applied by the regulator in the transmission sector in Brazil.

\subsection{Revenue cap reimbursement system}

In a revenue cap regime, a regulator can determine the probable costs of operations to fix the revenue for each agent (which in DEA is called decision making unit - DMU) for a pre- 
determined regulatory period of $K$ years $(k=1, \ldots, K)$. Bogetoft [3] gives the following formulation of the revenue cap reimbursement scheme, which closely represents the regulator's formula in Brazil:

$$
R C_{j}^{k}=C_{j} \cdot\left(1-X F-E f f_{j}\right)^{k} \quad k=1, \ldots, K
$$

In this formula, the revenue cap of a $\mathrm{DMU}_{j}$ in period $k$ is shown by $R C_{j}^{k}$. Let us assume that the review period includes $T$ years $(t=1, \ldots, T)$. Then, $C_{j}$ represents the level of historical costs of $\mathrm{DMU}_{j}$ reported in the last year $T$ of the review period. The efficiency $E f f$ of $\mathrm{DMU}_{j}$ can be computed, e.g., by DEA as benchmarking method on the basis of the reported data in year $T$. The above formula also includes $X F$ (i.e., the $\mathrm{X}$-factor), which reflects the productivity gain that can be expected across all DMUs in the sample (for more details, see Bogetoft [3]).

In the specific case of the Brazilian TSO regulation analysed in this paper, on the basis of the revenue cap formula given in (1), the review period includes the six years between 2009 and 2014 (i.e., $T=2014$ ). The estimate of the $\mathrm{X}$-factor is then used in the regulatory system for $K=5$ years from 2015 on. However, it should be noted that $C_{j}$ represents already the expected efficient costs of operations of $\mathrm{DMU}_{j}$ in the last year of the review period, i.e., $C_{j}=C_{j}^{e f f}$. Hence, according to Technical Note no. 266/2015 (p. 05) [5], the regulator applies the following modification of the above revenue cap formula:

$$
R C_{j}^{k}=C_{j}^{e f f} \cdot(1-X F)^{k} \quad k=1, \ldots, 5
$$

In order to estimate the $\mathrm{X}$-factor, regulators may apply an appropriate framework of the Malmquist index to monitor how the DMUs' productivity change over the review period. The results can be further decomposed in order to find the impact of the shift in the technology on the productivity, which is determined by the technical change component of the Malmquist index. For example, in the case of a $2 \%$ positive shift in the technology on average, the regulator would have a good indication to impose an $\mathrm{X}$-factor close to $2 \%$. This can be justified due to the fact that even the already efficient DMUs (i.e., benchmark DMUs) were able to produce the same level of outputs at lower costs within the review period. Hence, the other DMUs should also be 
able to improve and catch up in productivity over the regulatory period. In the following, we show how the Malmquist index and its components can be computed.

\subsection{Malmquist index and its components}

In the original form of the Malmquist index, it is assumed that $n$ firms (i.e., DMUs) are observed in $T$ years (i.e., over the review period). Let $X_{j}^{t}=\left(x_{1 j}^{t}, x_{2 j}^{t}, \ldots, x_{m j}^{t}\right)$ and $Y_{j}^{t}=\left(y_{1 j}^{t}, y_{2 j}^{t}, \ldots, y_{s j}^{t}\right)$ be non-negative and non-zero vectors, which quantify the level of inputs and outputs of $\mathrm{DMU}_{j}$ $(j=1, \ldots, n)$ in year $t(t=1, \ldots, T)$. Each technology in each year $t$ may satisfy non-emptiness, free disposability, convexity and CRS, which can be represented as

$$
T_{C R S}^{t}=\left\{\left(X^{t}, Y^{t}\right) \in \mathfrak{R}_{+}^{m} \times \mathfrak{R}_{+}^{s} \mid x_{i}^{t} \geq \sum_{j=1}^{n} \lambda_{j}^{t} x_{i j}^{t}, \quad y_{r}^{t} \leq \sum_{j=1}^{n} \lambda_{j}^{t} y_{r j}^{t}, \quad \lambda_{j}^{t} \geq 0, \quad \forall j, \forall t\right\} .
$$

Each technology in (3) can be extended to other technologies with VRS (shown by $T_{V R S}$ ) or NDRS (shown by $T_{N D R S}$ ): In the VRS variant of the technology, we add to (3) the normalizing equality $\sum_{j=1}^{n} \lambda_{j}^{t}=1$. In the case of NDRS, we replace the equality sign in $\sum_{j=1}^{n} \lambda_{j}^{t}=1$ by the inequality sign " $\geq$ ". Accordingly, the efficiency of a $\operatorname{DMU}_{j}(j=1, \ldots, n)$ observed in year $l$ $(l=1, \ldots, T)$ against a technology $T_{w}^{t}(t=1, \ldots, T)$ can be computed by the following input distance function

$$
\left[D_{w}^{\circ}\left(X_{j}^{l}, Y_{j}^{l}\right)\right]^{-1}=\sup \left\{\theta>0 \mid\left(X_{j}^{l} / \theta, Y_{j}^{l}\right) \in T_{w}^{t}\right\}
$$

where $w$ may be CRS, VRS or NDRS. We note here that $D_{w}^{6}\left(X_{j}^{l}, Y_{j}^{l}\right)$ represents the Farrell technical efficiency (see Farrell [22]), which is the reciprocal of the input distance function by Shephard [23]. In addition, $B_{w}^{0}\left(X_{j}^{l}, Y_{j}^{l}\right)$ can be computed by an appropriate DEA model (see, e.g., Färe et al. [7]). While the formula in (4) defines an input distance function, an output distance function can be defined similarly (see, e.g., Afsharian and Ahn [9]). 
Following Ray and Desli [1], the Malmquist index for $\operatorname{DMU}_{j}(j=1, \ldots, n)$ between two time periods $t$ and $t+1$ can be computed as

$$
\mathrm{MI}=\left[\frac{B_{C R S}^{6}\left(X_{j}^{t+1}, Y_{j}^{t+1}\right)}{B_{C R S}^{b^{+1}}\left(X_{j}^{t}, Y_{j}^{t}\right)} \times \frac{D_{C R S}^{\mathrm{b}}\left(X_{j}^{t+1}, Y_{j}^{t+1}\right)}{B_{C R S}^{\mathrm{b}}\left(X_{j}^{t}, Y_{j}^{t}\right)}\right]^{\frac{1}{2}}
$$

The result of the Malmquist index in (5) can also be exhibited by the multiplication of the pure efficiency change (PEC), technical change (TC) and scale efficiency change (SEC) components:

$$
\begin{aligned}
& \mathrm{PEC}=\frac{B_{V R S}^{b^{+1}}\left(X_{j}^{t+1}, Y_{j}^{t+1}\right)}{D_{V R S}^{\mathrm{b}}\left(X_{j}^{t}, Y_{j}^{t}\right)} \\
& \mathrm{TC}=\left[\frac{D_{V R S}^{\mathrm{b}}\left(X_{j}^{t}, Y_{j}^{t}\right)}{D_{V R S}^{6+1}\left(X_{j}^{t}, Y_{j}^{t}\right)} \times \frac{D_{V R S}^{\mathrm{b}}\left(X_{j}^{t+1}, Y_{j}^{t+1}\right)}{D_{V R S}^{\dagger+1}\left(X_{j}^{t+1}, Y_{j}^{t+1}\right)}\right]^{\frac{1}{2}},
\end{aligned}
$$

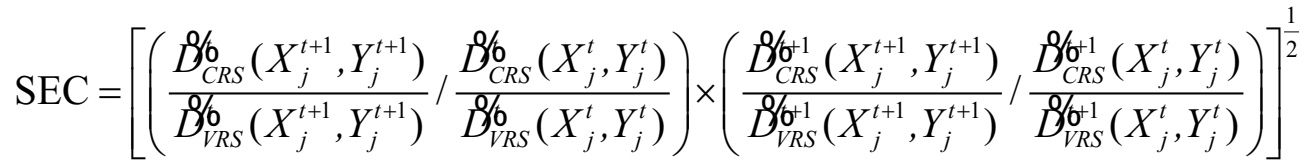

The PEC component captures whether the DMU under evaluation is closer to or further away from the border of the benchmark technology $T^{t+1}$ compared to its situation by taking into account the benchmark technology $T^{t}$. The TC component indicates whether the border of the technology has shifted over time, and the SEC component measures the effect of the change in scale of DMUs on their productivity. According to the definition of the distance function in (4), if the value of the Malmquist index or any of its components is less than one, it denotes regress; a value greater than one implies progress, while a value of one indicates an unchanged situation.

\section{Energy transmission regulation in Brazil}

Electricity in Brazil is predominantly produced by hydroelectric plants due to the country's characteristic of mountainous terrain and the abundance of water resources (brasil.gov.br [24]). These plants cover approximately $70 \%$ of the overall installed electricity capacity and $74 \%$ of the entire electricity generation (abradee.com.br [25]). As a second specificity, the Brazilian 
electricity sector, like in other emerging economies, has been shown to be strongly affected by political and economic influences (Pase [26]).

Within this sector, the transmission of electricity is the link that integrates generation and distribution, allowing the electric power system to act in a cohesive way (Instituto Acende Brasil [27]). The Brazilian energy transmission network has expanded by $45 \%$ in ten years until 2015 and has almost been doubled in the last 20 years, which results in an actual capacity of about 142.000 MW and $135.0000 \mathrm{~km}$ of transmission lines in total (ons.org.br [28]). Having shown to be one of the bottlenecks of the 2001 energy crisis, energy transmission in Brazil is expected to maintain its pace of expansion for at least the next decade (Instituto Acende Brasil [27]). Despite the investments already made and planned for the future, however, the sector faces challenges. Especially, regulatory issues have affected the investment capacity of large companies and caused difficulties in bidding on new projects (Montenegro [29]).

Until the end of the 1980s, the growth of the electricity sector in Brazil had been due to the public action in order to increase the supply of energy to the end-user customers (Pase [26]). This had also enabled the growth of the national infrastructure by providing energy for the country's industrial park and enhanced the urbanization process as well as people's access to public services (Pase [26]). Since the 1990s, along with the initiation of the democratic process in Brazil, reforms have begun in several sectors of the country (Gonçalves [30]). These reforms have included the insertion of private companies in the electricity sector through the so-called National Privatization Plan (Pinheiro and Fukasaku [31]). At the beginning of these reforms, 31\% of the capital of state-owned energy companies was transferred to the private sector (Gonçalves [30]).

The regulatory models in Brazil emerged in the 1990s, when the country went through the abovementioned privatization process of the state-owned utilities. In the electricity sector in particular, ANEEL was founded in 1997 as an independent regulatory agency with the objectives such as: promoting efficiency, maintaining the financial equilibrium of the concessions as well as controlling the quality of services delivered to customers (Lins et al. [21]). One of the early decisions to regulate effectively the sector was to treat electricity generation and commercialization as a free market while transmission and distribution were considered as a 
regulated market (Lins et al. [21]). In the following, the system of regulation was equipped first with a cost recovery regime (Resende [32]). Later on, the system changed to the so-called engineering process by which the revenue of both DSOs (i.e. distribution system operators) and TSOs were regulated by comparing them to ideal engineering-designed benchmarks. More recently, ANEEL has switched to mainly apply DEA-based incentive regulation in both the electricity distribution and transmission sectors (see Lopes and Lanzer [33]).

In the Brazilian transmission sector, ANEEL has been running a revenue cap system to regulate the market (Pessanha et al. [4]). In order to do so, the transmission assets are classified as "existing facilities" and "new facilities". The existing facilities are listed in ANEEL's Resolution No. 166/2000 and comprise the set of installations that already had been in operation before January 01, 2000 (imprensanacional.gov.br [34]). The installations which have been added from this date on constitute the new facilities. They are granted in auctions, in which interested investors compete for the concession of new transmission projects (Pessanha et al. [4]). On this basis, ANEEL divides the companies to be regulated into two groups, namely "old licensed companies" (OLCs) and "new licensed companies" (NLCs). The OLCs exclusively have the concession over the group of existing facilities (the ones already in operation before the beginning of 2000), but also operate new facilities. The NLCs are those companies that operate only new authorized facilities.

Over the last 20 years, the electric energy transmission sector (considering only NLCs) has undergone two tariff reviews (Technical Notes no. 338/2010 [35], 45/2012 [36] and 266/2015 [5]). Since 2010, the regulator has been estimating the X-factor to be included in the revenue cap system. In the following, we investigate the way the X-factor was determined in 2015 by ANEEL in the transmission sector concerning the review period 2009-2014. The regulator describes the respective details in the Technical Note no. 266/2015 [5] from Public Hearing ${ }^{1}$ no. 76/2015, which we take as a source for our considerations.

\footnotetext{
${ }^{1}$ ANEEL regularly promotes public audiences to discuss the tariff reviews. In these audiences, there is a call for contributions based on a preliminary Technical Note, which gives details of the regulator's methodology of the revenue cap system. For a certain period of time, the TSOs can propose suggestions for the improvement of the methodology. After this period of discussion, ANEEL publishes a final decision which may or may not include the TSOs' suggestions.
} 


\section{Critical overview of ANEEL's regulation approach}

\subsection{Problem setting}

The focus of this paper is on the way the X-factor was estimated by ANEEL, reported in the Technical Note no. 266/2015 [5] from Public Hearing no. 76/2015. On the basis of the revenue cap formula (2) given in Section 2.2, the review period includes the six years between 2009 and 2014 (i.e., $T=2014$ ) to estimate the $\mathrm{X}$-factor. ANEEL also includes both "old licensed companies (OLCs)" and "new licensed companies (NLCs)" in the sample, leading to $n=38$ TSOs. As input, the operational expenses (OPEX) are used. This input comprises expenses for personnel, administration, materials, outsourced services, leases and rents, insurances, taxes, and other operational costs. The outputs are network extension (thousands of $\mathrm{km}$ ), modules (number) and installed capacity (megavolt-ampere, MVA). ANEEL justifies the adequacy of this input-outputsets by the following reasons: 1) simplicity, 2) the strong correlation between the chosen variables and other candidate variables, 3) availability of the respective data in most companies (more details can be found in Technical Note no. 266/2015 [5]).

In order to analyze the productivity of the TSOs over the review period, ANEEL applies a modified version of the RD decomposition of the Malmquist index whose original framework was outlined in Section 2.3 In ANEEL's approach, the VRS assumption for the benchmark technology in the components of the Malmquist index has been replaced by NDRS. In particular, the TC component of the Malmquist index - which is used for the estimation of the X-factor - is measured as follows:

$$
\mathrm{TC}=\left[\frac{B_{N D R S}^{6}\left(X_{j}^{t}, Y_{j}^{t}\right)}{B_{N D R S}^{6+1}\left(X_{j}^{t}, Y_{j}^{t}\right)} \times \frac{B_{N D S S}^{6}\left(X_{j}^{t+1}, Y_{j}^{t+1}\right)}{B_{N D R S}^{6+1}\left(X_{j}^{t+1}, Y_{j}^{t+1}\right)}\right]^{\frac{1}{2}} .
$$

It should be emphasized that, by the above modification, the definition of the Malmquist index in ANEEL's approach remains the same as the one given in (5). One can straightforwardly check that the multiplication of the PEC, TC and SEC components generates the standard MI in (5) even if the distance functions with VRS (i.e., the RD decomposition) are replaced with NDRS (i.e., ANEEL's approach) in all the components. 
After having computed the Malmquist index and its components, ANEEL also adapts the bootstrapping method of Simar and Wilson [2] to generate a confidence interval for the initial estimates of the $\mathrm{X}$-factor.

\subsection{Overview of the results of the Malmquist index and its components}

In order to investigate ANEEL's approach to estimating the X-factor, we had access to the original R codes (available as the suplementary material) and the data that the regulator used for measuring the Malmquist index and its components as well as the confidence intervals using bootstrapping. The results reported in Technical Note no. 266/2015 [5] by ANEEL are shown in Table 1.

Table 1: Original results of the Malmquist index and its components by ANEEL

\begin{tabular}{ccccc}
\hline & $\begin{array}{c}\text { Malmquist } \\
\text { index }\end{array}$ & $\begin{array}{c}\text { Pure efficiency } \\
\text { change }\end{array}$ & $\begin{array}{c}\text { Technical } \\
\text { change }\end{array}$ & $\begin{array}{c}\text { Scale efficiency } \\
\text { Change }\end{array}$ \\
\hline $2009-10$ & 1.121 & 1.027 & 1.114 & 0.980 \\
$2010-11$ & 0.986 & 1.117 & 0.887 & 0.995 \\
$2011-12$ & 1.039 & 1.222 & 0.856 & 0.994 \\
$2012-13$ & 1.035 & 0.926 & 1.124 & 0.995 \\
$2013-14$ & 0.971 & 0.916 & 1.063 & 0.997 \\
\hline
\end{tabular}

Source: ANEEL (Technical Note no. 266/2015, p. 15) [5]

In contrast to these results reported by ANEEL, our analysis - on the basis of the RD decomposition of the Malmquist index and according to the modifications and the problem setting in Section 4.1 - has produced the results summarized in Table 2.

Table 2: Correct results of the Malmquist index and its components

\begin{tabular}{ccccc}
\hline & $\begin{array}{c}\text { Malmquist } \\
\text { index }\end{array}$ & $\begin{array}{c}\text { Pure efficiency } \\
\text { change }\end{array}$ & $\begin{array}{c}\text { Technical } \\
\text { change }\end{array}$ & $\begin{array}{c}\text { Scale efficiency } \\
\text { change }\end{array}$ \\
\hline $2009-10$ & 0.928 & 1.017 & 0.905 & 1.007 \\
$2010-11$ & 1.044 & 0.919 & 1.132 & 1.003 \\
$2011-12$ & 0.983 & 0.838 & 1.172 & 1.001 \\
$2012-13$ & 0.978 & 1.095 & 0.893 & 1.001 \\
$2013-14$ & 1.049 & 1.109 & 0.942 & 1.004 \\
\hline
\end{tabular}

A comparison of the Tables 1 and 2 reveals significant differences between the results of the Malmquist index and its components. Especially, the change in technology, which is substantial 
in both calculations, shows an inverse trend. In the following, we investigate the reasons behind these differences. We also analyze the way the X-factor was estimated on the basis of these results and explain why - in spite of the above-observed substantial technical changes - it has been set to zero by ANEEL. Furthermore, we discuss the practical implications and consequences of our findings.

\subsection{Distance functions and the corresponding efficiency scores}

Having thoroughly analyzed ANEEL's approach and the details of their computations, we have revealed a serious inaccuracy in the interpretation of the distance functions and accordingly the results of the Malmquist index and its components. As mentioned earlier in Section 4.1, we have found out that the regulator follows the steps necessary to formulate a modification of the Malmquist index from Ray and Desli [1]. However, in order to measure the input distance function, they do not apply $B_{w}^{b / b}\left(X_{j}^{l}, Y_{j}^{l}\right)$ in formula in (4), but the Shephard distance function as follows:

$$
D_{w}^{t}\left(X_{j}^{l}, Y_{j}^{l}\right)=\sup \left\{\theta>0 \mid\left(X_{j}^{l} / \theta, Y_{j}^{l}\right) \in T_{w}^{t}\right\} .
$$

With respect to (10), given $Y_{j}^{l}$, vector $X_{j}^{l}$ decreases as much as possible by scaling it by $\theta$ while remaining in a corresponding technology set $T_{w}^{t}$. Hence, a $\mathrm{TSO}_{j}$ is inefficient if and only if $D_{w}^{t}\left(X_{j}^{l}, Y_{j}^{l}\right)>1$. Compared to (4), this implies that we have $D_{w}^{t}\left(X_{j}^{l}, Y_{j}^{l}\right)=\left[B_{w}^{\circ b}\left(X_{j}^{l}, Y_{j}^{l}\right)\right]^{-1}$.

The consequence of using (10) instead of (4) in the computation of the Malmquist index and its components is now straightforward: if the value of the Malmquist index or any of its components is less than one, it denotes "progress"; a value greater than one implies "regress", while a value of one indicates an unchanged situation.

According to the Technical Note no. 266/2015 [5], it can be seen that ANEEL applies the Shephard distance function in (10), but interprets the results as if the Malmquist index was computed by the Farrell measure in (4). Hence, all the situations found by the regulator as "progress" should have been read as "regress" and vice versa. Alternatively, the results could 
have been inverted before any interpretation had been given. But none of these two paths have been followed by the regulator. In order to see how this serious misinterpretation has changed the managerial implication, consider the following example:

Fig. 1 shows the results of the change in the productivity obtained by ANEEL's approach in comparison to those which are computed by the approach described in Section 2.3 (see also Tables 1 and 2 in Section 4.2). As can be seen, e.g., the regulator has captured, on average, a progress of $12.1 \%$ in the productivity between 2009 and 2010 (i.e., $\mathrm{MI}=1.121)^{2}$. However, the correct result is a regress of $-7.2 \%$. (i.e., $\mathrm{MI}=0.928$ ). This example should highlight to what extent the results of the productivity change have been affected.

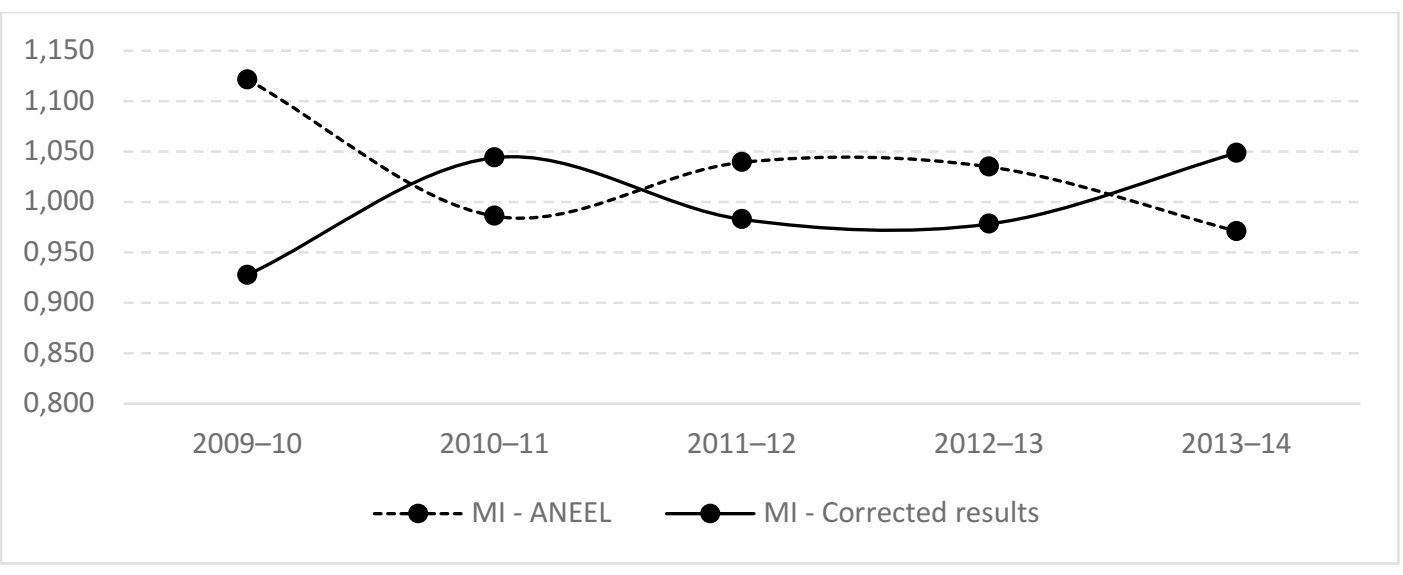

Fig. 1: Results of the productivity change obtained by ANEEL versus the corrected results

\subsection{Geometric mean vs. arithmetic mean}

The fundamental objective of ANEEL's approach is to estimate the X-factor for the transmission sector in Brazil. In order to do so, in the first step, the Malmquist index and its components are computed for each single TSO over the six years (i.e., five adjacent periods between 2009 and 2014) of the review period. The mean value of each component over all TSOs in each adjacent period is then used as an estimate of that component for the corresponding adjacent period (see Table 1 in Section 4.2). Regardless of the interpretation of the values (i.e., whether they indicate regress or progress; see Section 4.3), we have observed an additional measurement error in the determination of the components.

\footnotetext{
${ }^{2}$ There are other miscalculations (see the following sections) in ANEEL's approach which have led the result here to be 1.121 instead of the expected $1.078(=1 / 0.928)$.
} 
A closer look at the $\mathrm{R}$ codes for generating the results has revealed that the regulator applies an arithmetic mean instead of a geometric one for determining the averages. We note here that any individual result of a TSO is a growth rate so that the geometric mean is more appropriate than the arithmetic mean for describing characteristics and trends of the results over time. The geometric mean is also less sensitive to any outlier or a value which is atypical but may have carelessly been included in the computation. This miscomputation may be seen as a tiny mistake in the whole process of measuring productivity and its components. However, the error of this kind often significantly affects the final results, as shown now.

Fig. 2 compares the (values of the) changes of the Malmquist index and its components for the adjacent period 2010-11 determined within ANEEL's approach with those of our calculations, on which the geometric average has been applied (see Tables 1 and 2 in Section 4.2). It should be noted that, in Fig. 2, the values reported by the regulator have been inverted to overcome the issue of distance functions already discussed in Section 4.3, i.e., with this transformation of the results, the first problem is resolved. This makes our values in Fig. 2 comparable according to the issue being investigated in this section, meaning that a value greater than one implies progress and a value less than one represents regress.

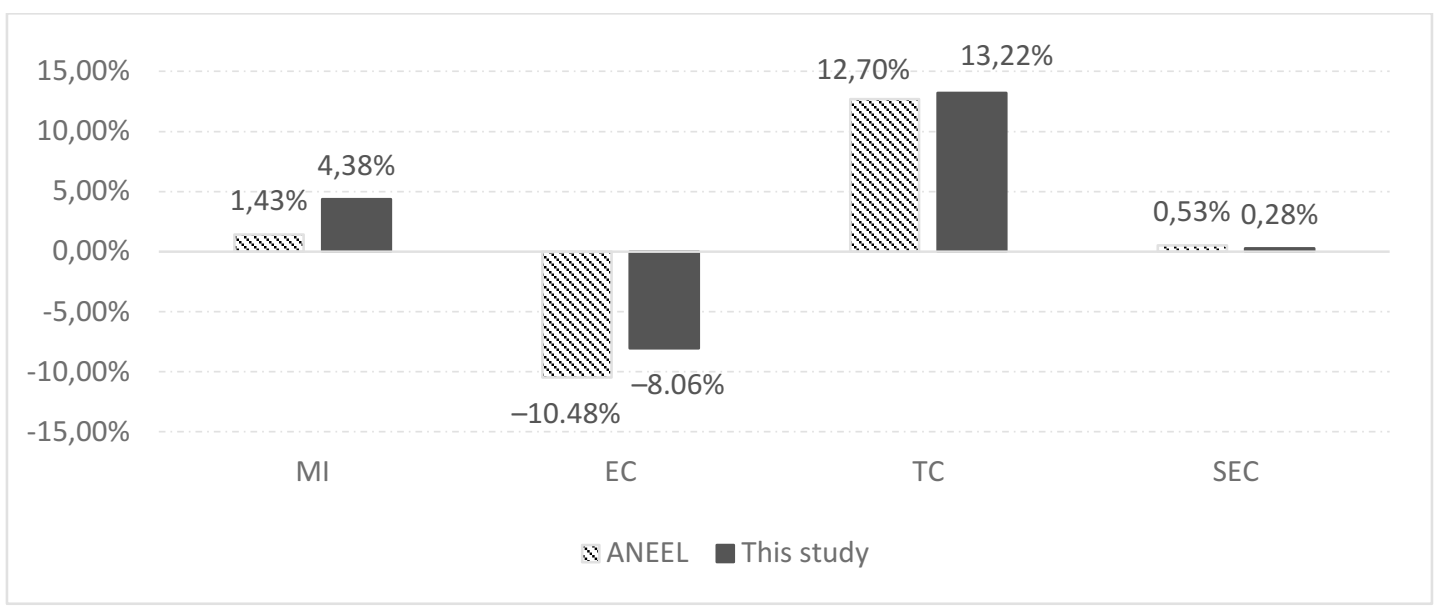

Fig. 2: Exemplary results of the Malmquist index and its components computed by ANEEL versus the corrected results concerning the adjacent period 2010-11

As can be observed in Fig. 2, for all components of the Malmquist index, we can see differences from the correct results ranging from $0.25 \%$ for SEC to $2.42 \%$ for EC. This represents how an error of this kind may change the final results significantly. Taking into account these results, one 
may also now expect that an arithmetic mean - calculated across all TSOs in a particular adjacent period - should also lead to inconsistency in the decomposition of the Malmquist index. According to the discussions in Section 2.3, we recall that any estimate of the Malmquist index computed by (5) should alternatively be generated by the product of its components given in (6)(8). The reason is that the Malmquist index is decomposed in a multiplicative form. Hence, applying an arithmetic mean (which has an additive nature) over TSOs in a particular adjacent period should normally create an inconsistency in the final results so that $\mathrm{MI} \neq \mathrm{EC} \cdot \mathrm{TC} \cdot \mathrm{SEC}$.

However, this particular inconsistency cannot be seen in the results reported by ANEEL (see Table 1 in Section 4.2). Having analyzed the details of the R codes, we have discovered that the SEC component is not computed directly by its formula in (8). In fact, the value of this component is extracted indirectly from the relation $\mathrm{SEC}=\mathrm{MI} / \mathrm{EC} \cdot \mathrm{TC}$. This avoids any inconsistency of this kind to be observed in the Brazilian regulator's reported final results, even though the other components (i.e. EC and TC) as well as the Malmquist index are estimated with a bias by means of an arithmetic mean. Turning back to the adjacent period 2010-11 as an example, our analysis on the basis of the original $\mathrm{R}$ codes from ANEEL shows that a direct computation of the SEC component with the same logic (i.e., using formula (8) and still applying an arithmetic mean) leads to a regress of $-2.68 \%$ rather than the reported value of $0.53 \%$. This means that $\mathrm{MI} \neq \mathrm{EC} \cdot \mathrm{TC} \cdot \mathrm{SEC}$. This example should highlight how a chosen form of average can even change the direction of the final results and also produce inconsistency in the decomposition of the Malmquist index.

\subsection{Interpretation of the technical change component as the $\mathrm{X}$-factor}

The results of the Malmquist index and its components reported by ANEEL were shown in Table 1. In order to estimate an X-factor for the sector, the regulator uses the mean value of the TC component over the entire review period, which has been reported finally as $0.22 \%$, i.e., the average $^{3}$ of $+11.4 \%,-11.3 \%,-14.4 \%,+12.4$ and +6.3 (see also Fig. 3 ). With this, ANEEL concludes that there is no significant evidence of change in the technology so that an appropriate estimate of the $\mathrm{X}$-factor is zero. In the following, we comment on the way this conclusion has been drawn. We note here that, in regard to the discussions in Sections 4.2 and 4.3, the corrected

\footnotetext{
${ }^{3}$ While an arithmetic mean has been used in the computation of the mean values reported in Table 1 (see Section 4.3), ANEEL applies a geometric mean over the entire period to estimate the X-factor.
} 
values are $+9.5 \%,-13.2 \%,-17.2 \%,+10.7 \%$ and $+5.8 \%$ (see also Fig. 3). It should also be emphasized that the following arguments are valid irrespective of whether the regulator's results or the corrected figures are taken as a basis.

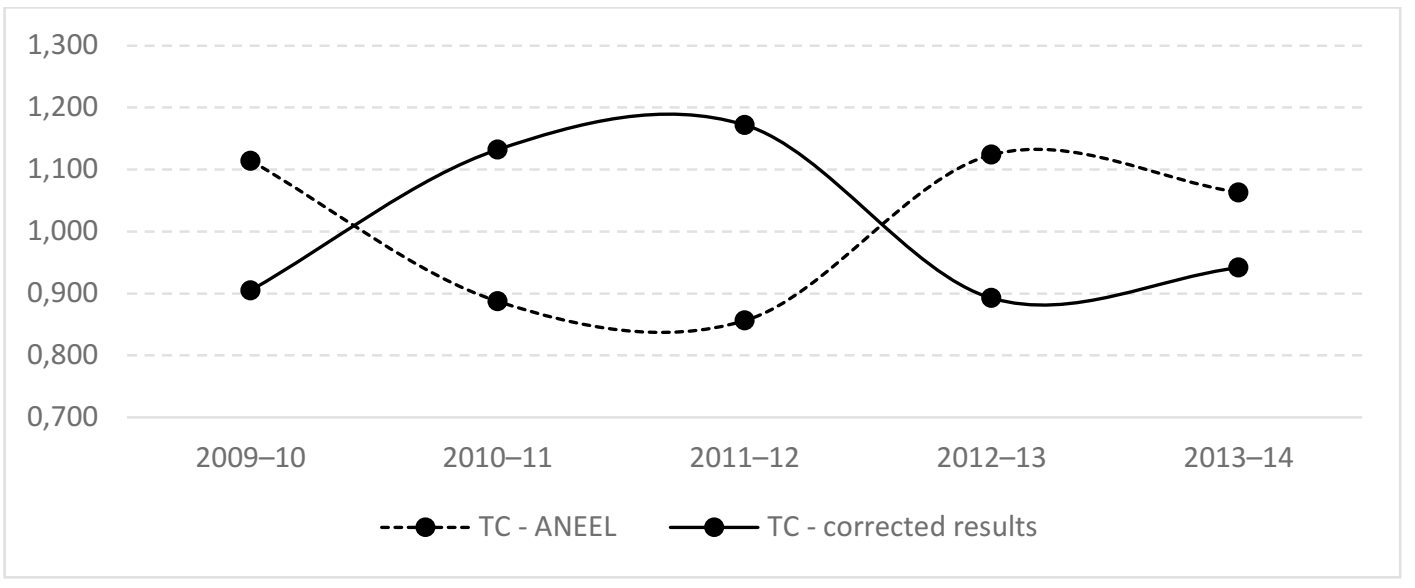

Fig. 3: Technical change component computed by ANEEL versus the corrected results

In order to apply the standard Malmquist index (see Section 2.3) and according to (2), ANEEL divides the entire review period into shorter time periods with the length of one year, i.e., $t=2009, \ldots, 2014$. This representation is motivated by the fact that all TSOs in each time period with the length of one year can be assumed to operate under the same technology (e.g., the same rules and regulations, economic conditions, etc.). Furthermore, it is assumed that the technology can change over time (otherwise there would be no reason to measure any technical change). Based on these assumptions and with the help of the Malmquist index and its decomposition, one can now check if there has been any change in the productivity (or its components) in each adjacent period.

The above-outlined discussion shows that computing the Malmquist index and its components once for each adjacent period and then reporting a single average across all years seems inconsistent with the objective of using the standard Malmquist index. Consider again the TC component. We can see both positive and negative values over time reported by ANEEL. As can be seen in Fig. 3, the results also fluctuate significantly. One may now argue that with such an aggregation (i.e., 0.22\%), valuable information can get lost and the final estimation becomes biased, respectively. Let us assume that we have some reasons for not including one of the figures of $\mathrm{TC}$ in the computation of the final average. Our reasons might be due to a shock in the 
market (like the world financial crises) or due to any substantial changes in the policies in the sector imposed by the government (see Section 4.7 for specific reasons in our context). In this case, the final estimation would be significantly different from $0.22 \%$. Further discussions about this estimation of the X-factor and the consequences on TSO's revenue are given in Section 4.7.

\subsection{Robustness of the estimations}

After having computed the Malmquist index and its components, ANEEL resorts to the bootstrapping method proposed by Simar and Wilson [2] to estimate a confidence interval for its initial estimate of the X-factor, reported as $0.22 \%$ (see Section 4.5 ). In the original framework of the bootstrapping method proposed by Simar and Wilson [2], a large number of randomly generated samples are created with replacements from the original dataset. Concerning our case,

each sample in each year produces new pseudo-technologies $\hat{T}_{C R S}^{t}$ and $\hat{T}_{N D R S}^{t}(t=2009, \ldots, 2014)$. These pseudo-technologies give then the possibility to have new estimates of the distance functions and accordingly the Malmquist index and its components for each TSO and over each adjacent period.

Subsequently, on the basis of the distributions of the estimates, one can test (with a selected significance level) if changes in productivity computed by the Malmquist index or the results of the components are significant in a statistical sense. For example, it can be statistically concluded that an estimated value of the Malmquist index (or any other components) for an individual TSO over a particular adjacent period is significantly different from unity at the 0.10 level (which would indicate no change in productivity at this level) if the corresponding interval of all estimates does not include unity (for more details, see Simar and Wilson [2]).

In line with the above procedure, 2000 samples are generated in ANEEL's approach. However, the regulator does not bootstrap the Malmquist index (or any of the components) for "each TSO" in each adjacent period. Instead, unlike in the original framework proposed by Simar and Wilson [2], "the mean value" of each component "across all TSOs" in each adjacent period has been bootstrapped. 
Take the technical change (TC) component of the Malmquist index as an example. The original framework of the bootstrapping supports the theory in which, e.g., 2000 pseudo-technologies can be generated in order to have new estimates of TC for each single TSO and over a particular adjacent period (e.g., period 2009-10). This produces for each $\mathrm{TSO}_{j}$ a confidence interval (CI) of $\mathrm{TC}$ in each period, i.e., $C I_{T C}^{2009-10}\left(\mathrm{TSO}_{j}\right), \ldots, C I_{T C}^{2013-14}\left(\mathrm{TSO}_{j}\right)$. As it has been shown in Simar and Wilson [2], their procedure, in this case, provides a consistent estimate of the underlying distribution of inefficiencies and accordingly yields consistent estimates of the Malmquist index and its components. Now, one can test "separately" if an estimated value of TC for an individual $\mathrm{TSO}_{j}$ in a particular adjacent period is significant.

In contrast, ANEEL applies the above procedure on the "mean value computed over all TSOs" to have a single confidence interval for the TC in each adjacent period, i.e., $C I_{T C}^{2009-10}\left(\underset{j=1, \ldots, 38}{\operatorname{mean}} \mathrm{TSO}_{j}\right)$ ,..., $C I_{T C}^{2013-14}\left(\underset{j=1, \ldots, 38}{\operatorname{mean}} \mathrm{TSO}_{j}\right)$. However, there is no supporting theory showing that the resulting estimates are correct and consistent. As our confidence intervals here somehow aggregate the intermediate results (i.e., the results of all TSOs in each period), we can even intuitively expect that it is very likely that each of these confidence intervals includes unity. Hence, this is not surprising that the regulator concludes that there is no statistical evidence of having a TC significantly different from unity. Therefore, the value of the $\mathrm{X}$-factor has been set to zero.

It should be emphasized that, due to the other inaccuracies in the computations discussed in the previous sections, already the initial results calculated by ANEEL were not correct. However, the above discussions are still valid as we comment here on the "procedure" of applying the bootstrap and the way the X-factor has been set rather than on the pure numerical results. Following this procedure, but with all other mistakes already corrected, would lead ANEEL to the same conclusion: there is no statistical evidence of having a TC significantly different from unity. From this analysis, therefore, it should be clear that ANEEL's procedure (regardless of the numerical results in this particular case) is unconvincing. In fact, the regulator should use the original bootstrapping framework (if needed) and follow our proposal to estimate the X-factor by considering all intermediate results (see Section 4.5). 


\subsection{Consequences caused by the current estimate}

As already shown in the previous sections, there are substantial fluctuations in the results of the Malmquist index and its components over the adjacent periods. See Table 2 in Section 4.2: Taking the TC component as an example, its value decreases from a significant technical growth in 2011-2012 (i.e., 17.2\%) to a dramatic regress in 2012-2013 (i.e., -10.7\%). These results indicate a breakdown in the sector triggered probably by external factors, e.g., substantial changes in rules and regulations, or in economic conditions, etc. Indeed, in our case, there was an unexpected renewal of electricity companies' concessions at the end of 2012. At that time, the Brazilian government decided to anticipate the renewal of the TSOs' concessions (which otherwise would have taken place only between 2015 and 2017), with the goal of reducing the price of energy in the country (ANEEL [37]). This renewal imposed a significant reduction in the TSOs' revenues (for more details, see Lopes and Lanzer [33]), affecting their operational and investment spending capacity (see Instituto Acende Brasil [27]).

The government's decision is reflected in the Provisional Directive no. 579/2012, later converted into Law no. 12.783/2013. This law affected many contracts for commercialization of energy in a way that DSOs - as the direct customers of TSOs - had to purchase energy from the short-term market, which incurred higher costs (Montenegro [29]; Marcondes et al. [38]). This, in turn, also led to an immediate drop of the stock values of the companies (Assunção and Takamatsu [39]). As an example, Eletrobras (the biggest electricity company in Brazil) lost 58\% of its market value after the announcement of the renewal anticipation (Sorima Neto and Setti [40]). Experts call this crisis "the September $11^{\text {th }}$ of the energy sector in Brazil", which caused a financial distress in terms of a debt of more than R $\$ 100$ billion to electricity companies until 2016 (Junges [41]). Part of this debt was later passed on to the end-user consumers by imposing higher electric energy tariffs (Montenegro [29]). This line of argument suggests that the regulator should have analyzed the results of the Malmquist index calculation in more detail by considering atypical changes in the industry to be appropriately incorporated into the final estimation of the X-factor.

Taking into account the fluctuations in the results, together with the breakdown in the sector outlined above, we suggest that the year 2013 (which is directly affected by this phenomenon in our case) be excluded from the analysis to estimate the X-factor. In this alternative scenario, the 
new result of the X-factor (computed as a geometric average of the remaining TC values in Table 2) reveals that there has been a positive shift in the technology of $6.3 \%$. This means that even the best performing TSOs have generally been able to improve their performance over time. The regulator, therefore, could have used this initial result of the change in the technology as a basis to estimate the X-factor. Needless to say, that there might have been good reasons to still adjust the X-factor. In several publications (including technical reports published by regulators in other countries), it is common to also consider other econometric or frontier approaches or even ad hoc decisions to end up with an appropriate estimate of the X-factor (see, e.g., Botasso and Conti [42]; Agrell et al. [43]; Mesquita [44]).

In many cases, regulators may choose, e.g., to impose a positive $\mathrm{X}$-factor at the beginning of the regulatory period. This is done under the assumption of anticipated existence of inefficiency in the sector, seeking to provide an incentive to improve the performance of the companies (Burns and Jones [45]). In this line, e.g., Resende [32] states that the X-factor in the Brazilian electricity sector should be set even higher than those in other countries, due to its peculiar market imperfection. Together with the presence of strong evidences for a special market phenomenon and the significant fluctuations in the results, it is surprising, however, that the Brazilian regulator only focused on the single average of the final results of the TC component to end up with an Xfactor of zero. In contrast, all the above-mentioned evidences strongly indicate to set a positive $\mathrm{X}$-factor in the Brazilian transmission sector so that the gains could have been shared with the society. Let us assume, e.g., that the regulator would have set the X-factor to be $3 \%$. This implies that, e.g., for each R\$ 100 of costs under regulation in one year, the consumers could have paid up to R\$ 3 less. This exemplifies how this naïve way of estimating the X-factor directly affects the social welfare in general, having the customers to pay a higher price for electricity than they were supposed to.

\section{Conclusions and final remarks}

In Brazil, as a key step in running the incentive regulation regime, the regulator, ANEEL, applies a DEA-based Malmquist index for estimating the X-factor, which reflects productivity gains across all companies involved in the industry. In this paper, we have investigated the way the Xfactor was estimated in 2015 by ANEEL in the transmission sector concerning the review period 
2009-2014. As it has been shown, the regulator has applied a modified version of the Malmquist index developed by Ray and Desli [1] and also adapted the bootstrapping method of Simar and Wilson [2] to generate confidence intervals for initial estimates of the X-factor. Analyzing ANEEL's approach, we have discovered a number of serious analytical and computational shortcomings. We have also shown that the X-factor could have been estimated significantly different than zero, so that the society could have benefited from the companies' gains.

It should be acknowledged that the process of estimating an $\mathrm{X}$-factor in incentive regulation is not an easy task for the Brazilian or any other regulator. The responsibility of the regulator is substantial, since there is not a simple mathematical formula to follow in order to estimate the Xfactor. Each regulator has its own understanding and experience working in a sector, and there is no sole way the Malmquist index should be used in this process. Some countries, such as Finland and Norway, used the Malmquist index to determine the X-factor directly (Mesquita [44]). The British regulator, as a pioneer of including this factor in regulation, makes an cross-sector and international X-factor comparison, and ultimately negotiates with the regulated companies (Pollit [46]). As long as the computation is correct, each regulator may use MI differently, sometimes just as an extra tool to confirm other results, sometimes as a main tool.

The complexity of a correct application of DEA and the Malmquist index is also a challenge. These methods have the potential to adequately represent the reality but need well-established criteria to produce trustworthy results. In-depth knowledge of the sector is an essential requirement in the demanding model building process. In that sense, Agrell and Bogetoft [11] suggest an interactive process between the regulator and the regulated firms to define the proper parameters for frontier estimation. Besides, especially in the case of TSO regulation, aggregating variables might be a necessary solution for dealing with different operating technologies when using DEA and MI as benchmarking tools. Lots of effort must be made on the model specification and investigation of the real cost drivers so the model does not distort the actual situation.

The regulator in Brazil could have done a more detailed analysis by generating results on company level and examining the productivity trends for the sector. By simply taking the average of the average, the whole effort of computing all the indices for all the years chosen is 
problematic, as it has been shown in this paper. As Førsund and Kittelsen [47] state, it is essential to choose those years in the sample that most likely represent the sector without external interference in the performance. In this respect, the Brazilian regulator should have further explored the results to avoid distorted conclusions that may have been caused by the discussed regulatory shock in 2012, also represented in the MI indices' fluctuation.

Further research could go deeper into the matter of the model development. Apart from the pitfalls described in this paper, there are some more topics that have to be explored. Examples are: the choice of variables for the model, outlier analysis, other metrics for estimating productivity change and forms of validation of a chosen model. The discussion provided so far shows that the X-factor estimation is not a trivial process and should have an extensive conceptual basis, as well as pragmatic choices that not only make sense to the sector but also provide a mechanism that benefits the whole system.

\section{Acknowledgments}

The authors thank the two anonymous reviewers for their helpful comments.

The first two authors gratefully acknowledge the financial support from the Deutsche Forschungsgemeinschaft (DFG) in the context of the research fund AH 90/5-1.

The third author appreciates the financial support from the Foundation for the Research Support in Minas Gerais (FAPEMIG; research fund APQ-02809-15), the Coordination for the Improvement of Higher Education Personnel (CAPES; research fund 999999.000003/2015-08) and the National Council for Scientific and Technological Development (CNPq; research fund 444375/2015-5). 


\section{References}

[1] Ray S, Desli E. Productivity growth, technical progress, and efficiency change in industrialized countries: reply. Am Econ Rev 1997; 87:1033-39.

[2] Simar L, Wilson PW. Estimating and bootstrapping Malmquist indices. Eur J Oper Res 1999; 115:459-71.

[3] Bogetoft P. Performance benchmarking: measuring and managing performance. Springer Science \& Business Media; 2013.

[4] Pessanha JFM, Mello MARF, Barros M, Souza RC. Avaliação dos custos operacionais eficientes das empresas de transmissão do setor elétrico brasileiro: uma proposta de adaptação do modelo DEA adotado pela ANEEL. Pesqui Operacional 2010; 30:521-45.

[5] ANEEL. Technical Note no. 266/2015-SRM/ANEEL (original in Portuguese). 2015. Available

at: http://www2.aneel.gov.br/aplicacoes/audiencia/arquivo/2015/076/documento/nt 266 atualizacao do par $\% \mathrm{C} 3 \% \mathrm{~A} 2$ metro de ganho de produtividade proret .pdf. Accessed in February 13, 2018.

[6] Caves DW, Christensen LR, Diewert WE. The economic theory of index numbers and the measurement of inputs, outputs and productivity. Econometrica: J Econ Soc 1982; 50:1393-414.

[7] Färe R, Grosskopf S, Lindgren B, Roos P. Productivity change in Swedish pharmacies 1980-1989: a nonparametric Malmquist approach. J Product Anal 1992; 3:85-101.

[8] Charnes A, Cooper W, Rhodes E. Measuring the efficiency of decision making units. Eur J Oper Res 1978; 2: 429-444.

[9] Afsharian M, Ahn H. The overall Malmquist index: A new approach for measuring productivity changes over time. Ann Oper Res 2015; 226:1-27.

[10] Färe R, Grosskopf S, Norris M, Zhang Z. American economic association productivity growth, technical progress, and efficiency change in industrialized countries. Am Econ Rev 1994; 84:66-83.

[11] Agrell PJ, Bogetoft P. Regulatory benchmarking: models, analyses and applications. Data Envel Anal J 2017; 3:49-91.

[12] Arango S. Simulation of alternative regulations in the Colombian electricity market. Socioecon Plann Sci 2007; 41:305-19.

[13] Nunez K. Electric utility deregulation: stranded costs vs. stranded benefits. J Account Public Policy 2007; 26:193-211.

[14] Laffont J-J, Tirole J. A theory of incentives in procurement and regulation; 1993.

[15] Shleifer A. A theory of yardstick competition. RAND J Econ 1985; 16:319-27.

[16] Agrell PJ, Bogetoft P, Tind J. DEA and dynamic yardstick competition in Scandinavian electricity distribution. J Product Anal 2005; 23:173-201.

[17] Demsetz H. Why regulate utilities? J Law Econ 1968; 11:55-65. 
[18] Littlechild SC. Regulation of British telecommunications' profitability: report to the secretary of state; 1983.

[19] Bernstein J, Sappington DEM. Setting the X factor in price-cap regulation plans. J Regul Econ 1999; 16:5-26.

[20] Liston C. Price-cap versus rate-of-return regulation. J Regul Econ 1993; 5:25-48.

[21] Lins MPE, Sollero MKV, Calôba GM, da Silva ACM. Integrating the regulatory and utility firm perspectives, when measuring the efficiency of electricity distribution. Eur J Oper Res 2007; 181:1413-24.

[22] Farrell MJ. The measurement of productive efficiency. J R Stat Soc Ser A 1957; 120:25390 .

[23] Shephard R. Theory of cost and production functions. Princeton: Princeton University Press; 1970.

[24] Portal Brasil. Potencial hidrelétrico brasileiro está entre os cinco maiores do mundo 2014. Available at: http://www.brasil.gov.br/infraestrutura/2011/12/potencial-hidreletrico-brasileiro-esta-entreos-cinco-maiores-do-mundo . Accessed in February 13, 2018.

[25] ABRADEE. Visão geral do setor: indústria da eletricidade. http://www.abradee.com.br/setor-eletrico/visao-geral-do-setor. 2015. Accessed in February 13, 2018.

[26] Pase HL. Políticas públicas e infraestrutura: a agenda do setor elétrico brasileiro. Rev Debates 2012; 6:107-27.

[27] Instituto Acende Brasil. Transmissão: o elo integrador. 2015. Available at: http://www.acendebrasil.com.br/media/estudos/2015 WhitePaperAcendeBrasil 15 Transmissao_Rev_1.p df. Accessed in February 13, 2018.

[28] ONS. O sistema em números. Capacidade instalada No SIN - 2016 / 2021. 2018. Available at: http://ons.org.br/pt/paginas/sobre-o-sin/o-sistema-em-numeros. Accessed in February $13,2018$.

[29] Montenegro S. Impacto da MP 579 deve continuar nos próximos anos. Canal Energ 2016:1-2. Available at: https:/www.canalenergia.com.br/noticias/28844488/impacto-da-mp579-deve-continuar-nos-proximos-anos. Accessed in February 13, 2018.

[30] Gonçalves Junior D. Reformas na indústria elétrica brasileira : a disputa pelas ' fontes' e o controle dos excedentes. Universidade de São Paulo, 2007.

[31] Pinheiro AC, Fukasaku K. A privatização no Brasil: o caso dos serviços de utilidade pública; 2000.

[32] Resende M. Relative efficiency measurement and prospects for yardstick competition in Brazilian electricity distribution. Energy Policy 2002; 30:637-47.

[33] Lopes ALM, Lanzer EA. Benchmarking using Data Envelopment Analysis: DEA in regulating electricity: the Brazilian case. Belo Horizonte; 2015.

[34] Diário da União. Resolução no. 166, de 31 de maio de 2000. Available at: http://pesquisa.in.gov.br/imprensa/jsp/visualiza/index.jsp?.jornal $=1 \&$ pagina $=24 \& d a t a=01 / 06 / 200$ 0. Accessed in February 13, 2018. 
[35] ANEEL. Technical Note no. 338/2010-SRE/ANEEL (original in Portuguese). 2010. Available http://www2.aneel.gov.br/aplicacoes/audiencia/arquivo/2008/068/documento/nota tecnica n $\%$ C 2\%BA_338-2010 licitadas.pdf. Accessed in February 13, 2018.

[36] ANEEL. Technical Note no. 45/2012-SRE/ANEEL (original in Portuguese). 2012. Available at: http://www2.aneel.gov.br/cedoc/nren2012490.pdf. Accessed in February 13, 2018.

[37] ANEEL. Technical Note 383/2012-SRE/ANEEL (original in Portuguese). 2012. Available http://www.mme.gov.br/documents/10584/1256596/nota tecnica 383.pdf/66855e1b-3854-4d6788c9-e7e070a7a950. Accessed in February 13, 2018.

[38] Marcondes FD, Pinheiro MMM, Munch MG. Impacto da crise hídrica e da MP-579 no desempenho econômico-financeiro das empresas de distribuição de energia elétrica do Brasil. XXII Seminário Nacional de Distribuição de Energia Elétrica, 2016.

[39] Assunção TN, Takamatsu RTGFB. Os impactos da medida provisória 579 nos retornos das ações de companhias de energia elétrica. Gestão, Finanças e Contab 2015; 5:42-60.

[40] Neto JS, Setti R. Eletrobras perde 58\% de seu valor desde a MP 579 2012. Available at: https://oglobo.globo.com/economia/eletrobras-perde-58-de-seu-valor-desde-mp-579-6784779. Accessed in February 13, 2018.

[41] Junges C. Caos do setor elétrico já custou mais de R 110 bilhões em quatro anos. Gazeta Do Povo - Energia e Sustentabilidade 2016. Available at: http://www.gazetadopovo.com.br/economia/energia-e-sustentabilidade/caos-do-setor-eletrico-ja-custoumais-de-r-110-bilhoes-em-quatro-anos-en3kmuzuyr4jv2313kw255j6e. Accessed in February 13, 2018.

[42] Bottasso A, Conti M. Quantitative techniques for regulatory benchmarking. 2011. Available at: http://www.cerre.eu/sites/cerre/files/110509_CERRE_Study_Econometrics.pdf. Accessed in February 13, 2018.

[43] Agrell PJ, Bogetoft P. E3GRID2012 - European TSO benchmarking study. 2013. Available

at: https://www.researchgate.net/publication/265592571 E3GRID2012 European TSO Benchmark ing Study. Accessed in February 13, 2018.

[44] Mesquita R de B. Regulação de tarifas de distribuição de energia elétrica: uma análise comparativa entre reguladores europeus e latino-americanos. Universidade Federal de Minas Gerais; 2017.

[45] Burns P, Weyman-Jones T. The long-run level of X in RPI-X regulation: Bernstein and Sappington revisited; 2008.

[46] Pollitt M. The role of efficiency estimates in regulatory price reviews: Ofgem's approach to benchmarking electricity networks. Util Policy 2005; 13:279-88.

[47]Førsund FR, Kittelsen SA. Productivity development of Norwegian electricity distribution utilities. Resour Energy Econ 1998; 20:207-24. 